Dear Author,

Please, note that changes made to the HTML content will be added to the article before publication, but are not reflected in this PDF.

Note also that this file should not be used for submitting corrections. 


\title{
Body fatness and endogenous sex hormones in the menopausal transition
}

\author{
Annamaria Zsakai ${ }^{a, *}$, Zsolt Karkus $^{\mathrm{a}}$, Katinka Utczas ${ }^{\mathrm{a}}$, Beata Biri ${ }^{\mathrm{b}}$, Lynnette L. Sievert ${ }^{\mathrm{c}}$, \\ Eva B. Bodzsar ${ }^{a}$ \\ a Department of Biological Anthropology, Eotvos Lorand University, Pazmany P. s. 1/c, 1117 Budapest, Hungary \\ ${ }^{\mathrm{b}}$ Department of Biochemistry, Eotvos Lorand University, Pazmany P. s. 1/c, 1117 Budapest, Hungary \\ ' Department of Anthropology, UMass Amherst, 217 Machmer Hall, 240 Hicks Way, Amherst, MA 01003, USA
}

\section{A R T I C L E I N F O}

\section{Article history:}

Received 15 October 2015

Received in revised form 9 February 2016

Accepted 10 February 2016

Available online $\mathrm{xxx}$

\section{Keywords:}

Reproductive ageing

Menopausal status

Female sex hormone levels

Body fat mass

\begin{abstract}
A B S T R A C T
Background: Age at the final menstrual period is of clinical and public health interest because the age at which natural menopause occurs may be a marker of ageing and health, and in general the menopausal transition increases the risk of many diseases, e.g. redistribution in the pattern of adiposity during the menopausal transition may increase risk of metabolic disease. The purpose of this research was to study the relationship between the menopausal status and body fatness.

Subjects and methods: A random sample of 1932Hungarian women was studied. Body composition was estimated by body impedance analysis. In a subsample free estradiol and progesterone levels in saliva were quantified.

Results: Body fat mass increased until the late 50s and then had a decrease through senescence. Premenopausal women who were much older than the median age at menopause had a higher amount of fat than their postmenopausal age-peers, while postmenopausal women, whose menopause occurred much earlier than the median age at menopause, had less fat than their premenopausal age-peers. The body fat mass in premenopausal women with low levels of sex hormones was always below the agemedian value of the menopausal status subgroups, while the body fat mass of postmenopausal women with high levels of sex hormone levels was above the age-median values.

Conclusions: The analysis of body fatness in the menopausal transition revealed that (1) the rate of reproductive ageing and the body fat pattern were significantly related, and (2) body fat mass of women with unexpected levels of sex hormones was related more to their hormonal levels than to their menopausal status or their age. Thus future epidemiological screenings of women exposed to higher levels of menopause-related health risks should be expanded beyond the estimation of menopausal status based only on menstrual history to include sex hormone level assessment, as well as body composition analysis.
\end{abstract}

@ 2016 Published by Elsevier Ireland Ltd.

\section{Introduction}

Total body mass and the relative mass of tissue components are influenced by genetic and environmental factors (e.g., lifestyle, psychosocial, and sociocultural factors) and their interactions [1]. The body fat content of the human body is regulated by the neuroendocrine system through the whole life span, and can be maintained in a rather stable condition if the control of balance between energy intake and expenditure is appropriate. The neu-

\footnotetext{
* Corresponding author.

E-mail addresses: zsakaia@elte.hu (A. Zsakai), karkus@apaczai.elte.hu (Z. Karkus), utczas.katinka@gmail.com (K. Utczas), biri.beata@gmail.com (B. Biri), leidy@anthro.umass.edu (L.L. Sievert), bodzsar@elte.hu (E.B. Bodzsar).
}

roendocrine system regulates the energy balance through (1) the activity level of the autonomic nervous system, (2) the secretion of hormones (e.g., growth hormone, thyroid, insulin, sex steroids, leptin, adiponectin, resistin, ghrelin) and (3) physical activity and nutritional behaviours [2-4].

Adipose tissue serves not only as an energy storage site, an insulating layer and a mechanical protective layer, but also serves as an endocrine organ since several hormones (e.g. leptin, adiponectin, resistin, estrogens) are produced by this tissue. Almost all of the health-related changes in the location and amount of adipose tissue by age can be explained by all of these functions of the tissue, e.g. the increased adipose storage during pregnancy serves lactation after pregnancy. Women in different reproductive stages are exposed to different hormonal environments. It is evidenced that, due to the changing sex hormonal levels, the transitions 
between these stages are accompanied by significant changes in metabolic status and body structure and, as a consequences of these changes, the transitions are also accompanied by changes in general health status and quality of life as well [5-11]. There is much evidence for the relationship between an increase in overall morbidity and mortality and early or late ages of onset of the menopausal transition, e.g. an association of premature menopause (due to the subsequent oestrogen deficiency) with the increased risk of cardiovascular [11-14] and autoimmune diseases [14,15], osteoporosis [16,17], neurological diseases and psychiatric diseases $[18,19]$ has been confirmed $[11,14,15,20-23]$, while women experiencing menopause at a late age are at a higher risk of breast cancer [24,25] and abdominal obesity [20-23].

Although there is evidence that ageing is associated with reduced energy expenditure (in all of its components, such as physical activity, basal metabolism and adaptive thermogenesis) [26-28], levels of sex hormones decrease dramatically during the menopausal transition, and body fat distribution changes in relation to reproductive ageing due to this change in hormone production in women. However the biological processes that lead to changes in body fat distribution during the menopausal transition, i.e., an increase of total and central body fat (in particular an increase in the accumulation of intra-abdominal fat) and a redistribution of fat from lower body subcutaneous fat toward the abdominal region [29-31] have not been fully explored [32,33]. In addition, the changes in body fat distribution by age and during the menopausal transition cannot be studied independently (the increase in relative body fat mass and the increase in abdominal fat accumulation are the main features of body fatness redistribution by ageing) [29,34-36].

The main purpose of the present study was to analyze the changes in body fat mass in relation to age and menopausal status. The menopausal status of subjects was estimated on the basis of menstrual history parameters. In addition, free estradiol and progesterone levels in saliva were quantified in a subsample of subjects. Serum samples cannot be usually collected in epidemiological surveys. That is why the salivary level of the studied sex hormones has not been analysed in a larger sample. To achieve the main purpose of the study (1) body fatness (fat mass and fat distribution) of women was described by ageing and menopausal status, and (2) body fatness of subjects whose sex hormone levels were out of the normal interval of their menopausal status category were analysed.

\section{Subjects and methods}

\subsection{Sample}

After anthropometric, body composition and osteometric examinations, women ( $\mathrm{n}$ : 1932, aged $35+$ years; Table 1 ) were interviewed by questionnaires concerning their reproductive and menstrual history, socio-demographic background, lifestyle (habitual physical activity and nutrition), health conditions and subjective health. The subsample of women who participated in the saliva estradiol and progesterone estimation consisted of 173 subjects (Table 1 ). The presented cross-sectional survey was carried out between 2011 and 2014. Sample selection was done by considering the recommendations of the Sampling and Methodology Section of the Hungarian Central Statistical Office, which were based on the population statistics of the administrative territories and design-statistical regions.

Women who had any diseases or were taking any medications known to affect body composition, or who were hysterectomized or ovariectomized, were not included in the analysis. Only those women who had not used hormonal contraceptives or other sex hormones in the last year were asked to collect saliva samples for sex hormone level estimations.

All subjects were asked to give their informed consent to participate in the study. All participants were provided with detailed information on the main purposes of the study and on all examinations before their approval. The participation was voluntary and anonymous. The research objectives, the research methodology and the questionnaires were approved by the National Human Research Ethics Committee (108/2011) and the Hungarian Scientific Research Fund (EIK-1001/2011).

\subsection{Methods}

Subjects were divided into premenopausal, early and late perimenopausal and postmenopausal subgroups on the basis of their menstrual cycle characteristics (the occurrence of irregular periods and the age of last menstrual period; Table 1):

- premenopausal status: menstrual period in the past 3 months and no decreased predictability,

- early perimenopausal status: menstrual period in the past 3 months but less predictability in the preceding 12 months,

- late perimenopausal status: menstrual bleeding in the past 12 months but not in the past 3 months, and.

- postmenopausal status: amenorrheic for the past 12 months and no hysterectomy.

The age of natural menopause was estimated retrospectively by considering the age at the last menstrual cycle in the postmenopausal subgroup (median age at menopause was 51.60 years, 95\% confidence interval: $50.78-52.40$ years, probit analysis) [37]. Subjects were divided into 10-year long birth cohorts. Subjects were divided into "too early," "normal" and "too late" menopause on the basis of the age at normal menopause. Premature menopause was diagnosed by the cessation of menstruation before the age of 40 years, in accord with the scientific literature, while "too late" menopause was defined as when the final menstruation period occurred after the age of 60 years [38,39].

The subjects in the subgroup selected for hormonal level estimations were categorized on the basis of their sex hormone levels. Due to the financial conditions of the study, saliva samples could be collected from altogether 200 subjects. The subjects in this subgroup were selected randomly, to achieve an adequate distribution of the subgroup by age and menopausal status. Finally sex hormone level estimation could be made in 173 women. In the other 27 women, the saliva was not the appropriate amount, consistency or colour, or an impossible menstruation status assessment excluded the collected sample from the hormone level estimation.

It is obvious that the levels of female sex hormones show cyclic fluctuations during reproductive life, and only one estimation of hormonal levels is not enough to divide subjects into menopausal status subgroups even in the context of the average length of menstrual cycle and date of the last menstruation. Our aim was only to identify those subjects whose hormonal levels were unexpected for their menstrual status determined on the basis of menstrual cycle patterns, i.e. premenopausal women (n: 12) whose hormonal levels were too low or postmenopausal women (n: 26) whose hormonal levels were too high for their menopausal status.

The levels of free estradiol and free progesterone were estimated by the $17 \beta$-Estradiol (RE52601) and Progesterone (RE52281) Saliva ELISA kits of IBL (Hamburg, Germany). Saliva samples were collected with commercially available equipment. Subjects were asked to avoid eating, drinking, chewing gum or brushing their teeth for $30 \mathrm{~min}$ before sampling. Saliva samples were collected between 10.00 and 12.00 in the morning, stored at $-20^{\circ} \mathrm{C}$ (no longer than 2 months before the assays), warmed up to room tem- 
Table 1

The distribution of subjects by birth cohort (A) and menopausal status (B).

\begin{tabular}{|c|c|c|c|c|}
\hline & \multicolumn{2}{|c|}{ Total sample } & \multicolumn{2}{|c|}{ Subsample for hormonal level estimations } \\
\hline & $\mathrm{N}$ & $\%$ & $\mathrm{~N}$ & $\%$ \\
\hline \multicolumn{5}{|l|}{ (A) Birth cohort } \\
\hline 1920 & 320 & 16.6 & 0 & 0 \\
\hline 1930 & 347 & 18.0 & 21 & 12.1 \\
\hline 1940 & 275 & 14.2 & 25 & 14.5 \\
\hline 1950 & 357 & 18.5 & 31 & 17.9 \\
\hline 1960 & 256 & 13.3 & 49 & 28.3 \\
\hline 1970 & 192 & 9.9 & 30 & 17.3 \\
\hline 1980 & 185 & 9.6 & 17 & 9.9 \\
\hline Together & 1932 & 100.0 & 173 & 100.0 \\
\hline \multicolumn{5}{|l|}{ (B) Menopausal status } \\
\hline Premenopausal & 475 & 24.6 & 71 & 41.0 \\
\hline Early perimenopausal & 53 & 2.7 & 11 & 6.4 \\
\hline Late perimenopausal & 51 & 2.6 & 14 & 8.1 \\
\hline Postmenopausal & 941 & 48.7 & 77 & 44.5 \\
\hline Hyster- or ovariectomized & 401 & 21.3 & 0 & 0 \\
\hline Unknown status & 11 & 0.6 & 0 & 0 \\
\hline Together & 1932 & 100.0 & 173 & 100.0 \\
\hline
\end{tabular}

perature and centrifuged to separate the mucins. All standards, samples and controls were run in duplicate, the absorbance of each well was determined with an Epoch 267860 microtiter plate reader at $450 \mathrm{~nm}$. Four subjects (a 23-year-old and a 40-year-old premenopausal women, a 50-year-old perimenopausal woman and a 67-year old postmenopausal woman, whose menopausal status was estimated on the basis of menstrual bleeding patterns) were asked to collect saliva samples through a 42-day long interval. They were expected to have the normal hormonal level intervals for the menstrual status subgroups. The IBL Company also defined the expected values of menopausal subgroups-but only for pre- and postmenopausal subgroups between 21 and 75 years. By considering these recommendations and measured intervals, subjects could be divided into those with high and low levels of free estradiol and progesterone levels in the saliva (e.g. women of premenopausal status generally demonstrate a level of progesterone above $200 \mathrm{pg} / \mathrm{ml}$ and a level of estradiol above $15 \mathrm{pg} / \mathrm{ml}$, while women of postmenopausal status generally demonstrate a level of progesterone below $90 \mathrm{pg} / \mathrm{ml}$ and a level of estradiol below $1.3 \mathrm{pg} / \mathrm{ml}$ ). Women having high levels of both sex hormones were assigned into the subgroup with high levels of sex hormones, while women having low levels of both sex hormones were assigned into the subgroup with low levels of sex hormones.

The body fat fraction was estimated by body impedance analysis (NutriGuard M device, DataInput, Germany). Following the WHO recommendation, the waist-to-hip ratio was used to assess the body fat distribution [40].

The computations and the statistical analyses were carried out using SPSS v. 20. Due to the small groups of women in the intercentile ranges, the Fisher exact test was used to compare the expected and observed distributions. Hypotheses were tested at the $5 \%$ level of random error. The centile curves of body fatness were estimated by using lmsChartMaker Pro 2.3 software (Medical Research Council, UK 1997-2006; [41]) based on the LMS method, which utilizes the power transformation family of Box and Cox to allow the skewness of the measurement distribution, as well as the median and variability, to vary with age [42].

\section{Results}

\subsection{Age changes in the levels of endogenous estradiol and progesterone hormones}

Since the salivary sample collection was not done in the same phase of the menstrual cycle in women belonging to the reproduc- tive subgroup, the variation of the hormonal levels in this subgroup is obviously much wider than in the postreproductive subgroup, but a tendency by age can be observed in the case of both hormonal levels. The salivary levels of both sexual hormones decreased by age, but this decrease was observed from the early 40 s in the progesterone level while from the late $40 \mathrm{~s}$ in the estradiol level (Fig. 1, individual hormone levels are presented in Fig. 1. only for those women whose sex hormone levels were consistent with their menopausal status).

\subsection{Body fat mass}

The tendency for changes in body fat amount with age was very similar in the absolute and relative fat mass both in the total group and in all the menopausal subgroups of women (Fig. 2). By considering the age changes in body fatness independently of menopausal status it can be stated that the amount of body fat increased by age until the early 60s in women and showed an intensive decrease from the early 70s. Those women whose menopause occurred much earlier than the median age at menopause had a considerably lower amount of body fatness. While those women who had not yet experienced the menopausal transition after the estimated median age at menopause had a much higher body fat mass than those women who belonged to the menopausal status subgroups. The median curve of the pre- and perimenopause women differed from the central tendency of postmenopausal women not only in its higher values but also in its path, because the plateau in body mass that could be observed in postmenopausal women did not appear in women going through menopause at later ages (Fig. 2).

Both the relative and absolute body fat mass median curves of women with premature menopause showed similar tendencies as the general tendency of postmenopausal women (Fig. 2) with the exception of the age interval between 55 and 80 years: women with a too early menopause had smaller amount of body fat than women with a normal age at menopause in this age interval. The WHR median curve of women with premature menopause did not deviate from the curve of postmenopausal women (the WHR curve of women experiencing premature menopause therefore was not presented in Fig. 2).

\subsection{Body fat distribution}

The waist to hip ratio (WHR) of women showed a slight increase until the beginning of the $60 \mathrm{~s}$ in women and then stabilized around the value of 0.88 . The median curve of WHR reached the critical 

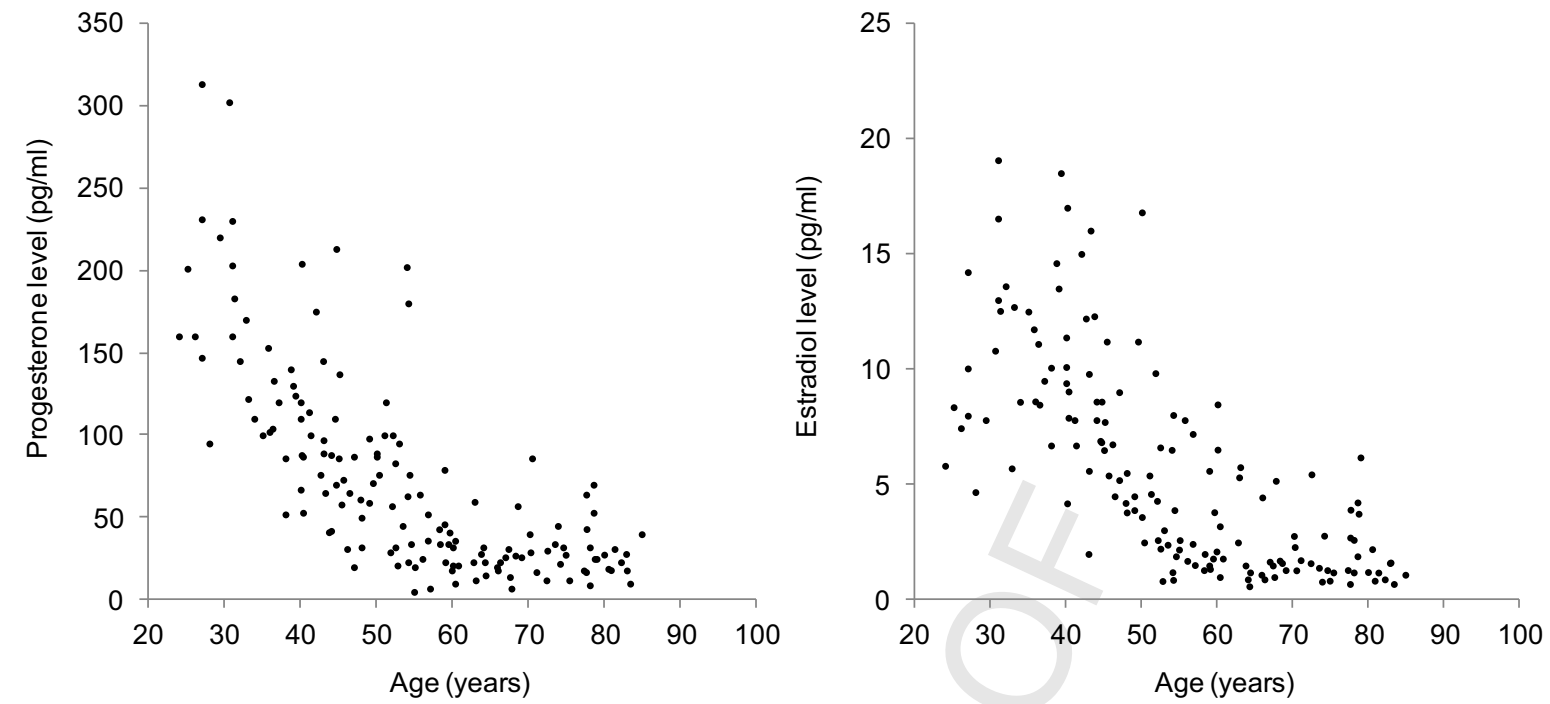

Fig. 1. Individual sex hormone levels of women (whose menopausal statuses estimated on the basis of sex hormone levels and menstrual history were equal).
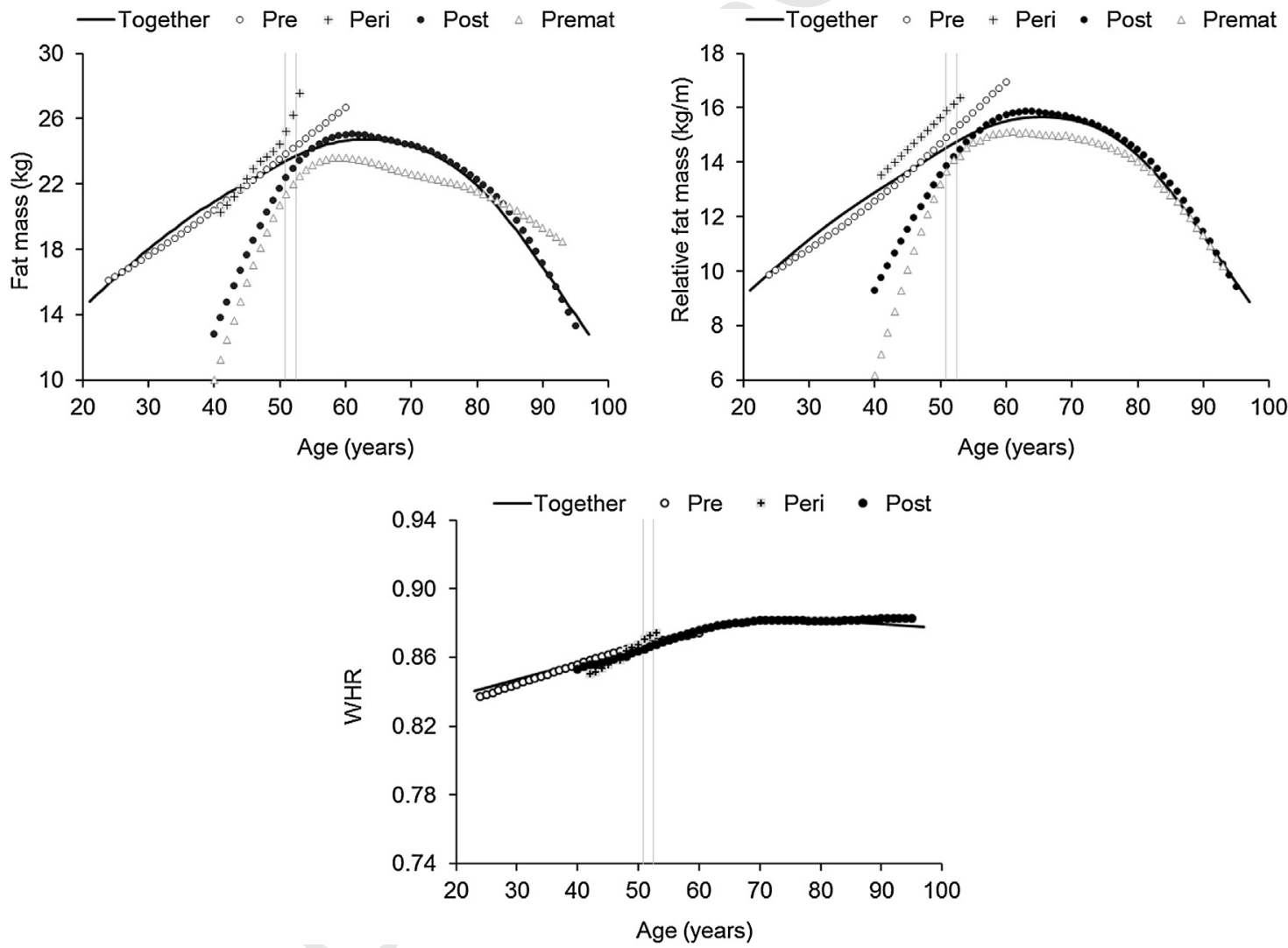

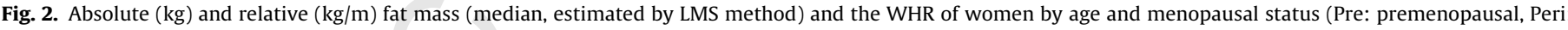

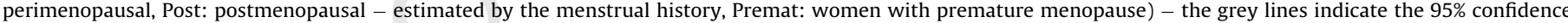
interval (50.78-52.40 years) of median age at menopause (51.60 years) in the studied sample of Hungarian women.

value of abdominal obesity (abdominal obesity: WHR $\geq 0.85$, [25]) in the 40s among Hungarian women. The median curves of WHR did not show considerable differences among the menopausal subgroups (Fig. 2).

\subsection{Body fatness and levels of endogenous estradiol and} progesterone hormones

By considering both indicators of body fatness (absolute and relative fat mass), it could be observed that the distribution of indi- vidual body fat mass among postmenopausal women (based on menstrual history: who were amenorrheic for the past 12 months not because of hysterectomy), and whose levels of sex hormone were higher than women usually have after the age at menopause, significantly differed from the distribution of body fat mass among the postmenopausal subgroup (Fig. 3). Contrary to this observation, those premenopausal women, whose levels of sex hormone were lower than premenopausal women's average levels, had lower level of body fat mass than their premenopausal age-peers (Fig. 3). 



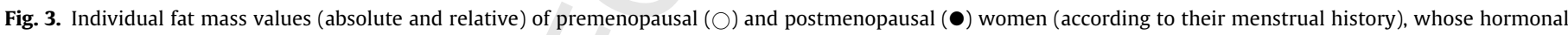

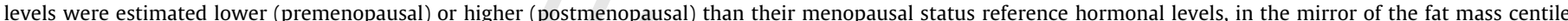

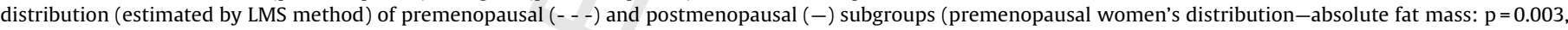
relative fat mass: 0.022 , WHR: 0.058 ; postmenopausal women's distribution-absolute fat mass: $p=0.006$, relative fat mass: 0.005 , WHR: 0.910 ; Fisher exact test).

The regional fat distribution on the trunk (WHR) of postmenopausal women having higher levels of sex hormones did not differ from their age-peers (Fig. 3), while the waist-to-hip ratio of premenopausal women with lower levels of sex hormones was significantly higher (and higher than the critical value of abdominal obesity) than their premenopausal age-peers (Fig. 3).

\section{Discussion}

The menopausal transition is associated with significant changes in body composition (e.g. body fat distribution, bone mineral density), in physiological status (e.g. increased frequency of psycho-somatic symptoms, dysregulation of the hypothalamicpituitary-gonadal axis, muscle sympathetic nerve activity) and metabolism (resting metabolic rate, fasting insulin levels, changes in the lipid profile and IGF-I level). These somatic changes and the general ageing processes of the body together lead to changes in lifestyle (e.g. decreasing physical activity during leisure time) and quality of life $[29,31,43-47]$.
Previous studies of body composition changes during the menopausal transition confirmed a menopause-related (1) increase in body adiposity, which is accompanied by redistribution of fat tissue to the intra-abdominal region, (2) and a decrease in fat-free mass due to decrease of skeletal muscle mass and bone mineral density [29,30,37,48-51].

Numerous epidemiological studies have shown that obese people are at increased health risk [52-58]. Morbidity and mortality risk is associated with obese nutritional status due to the comorbidities of obesity (e.g., insulin resistance, glucose intolerance, diabetes mellitus, cardiovascular diseases, sleep apnea, arthritis, certain types of cancer) [59-70]. In addition, abdominal obesity was found to increase the prediction of health risk in obese nutritional status [71-79].

International comparisons reveal that the age at menopause shows little variation in its occurrence (ranges between 48 and 52 years) across the European populations (Belgium: 49.98 years, France: 50.87 years, Italy: 50.90 years, Norway: 52.79 years, Poland: 51.30 years, Spain: 50.09 years, Switzerland: 50.28 years, UK: 51.15 years) [80-86]. The median age at last menstruation period, esti- 
mated from a probit model of the age at menopause, was 51.6 years in the studied sample. This estimation of the age at menopause in Hungary fits this European interval and the former meta-analysis estimation of age at menopause for the European region (50.79 years) [87].

The results of the present analysis revealed that age at menopause and body fatness were significantly related, namely the body mass of women with early menopause was smaller until the age of 50-55, while body fatness of women with late menopause was higher from the age of 50-55 than in women who experienced the final menstrual period in the normal age range. The body fat distribution in the studied age interval was unaffected by an early or late menopause transition in the studied sample.

Those women whose menopause occurred much earlier than the median age at menopause had a considerably lower amount of body fatness. While those women who had not yet experienced the menopausal transition after the estimated median age at menopause had a much higher body fat mass than those women who belonged to their menopausal status subgroups. The median curve of the pre- and perimenopause women differed from the central tendency of postmenopausal women not only in its higher values but also in its path, because the plateau in body mass that could be observed in postmenopausal women did not appear in women going through menopause at later ages.

The redistribution of body fat tissue during the menopausal transition has been studied by age and menopausal status independently until now, but not by considering the combined effect of age and menopausal status. The shift toward abdominal obesity after the last menstrual period, which was a general tendency evidenced by former menopausal studies [29,34-36], could not be confirmed in women with early or late menopause in the present analysis. A future longitudinal study of menopausal women's body composition could reveal whether a relation exists between the rates of reproductive ageing, namely the age at menopause and physique as has been evidenced in the case of menarcheal age, the age at the beginning of reproductive capacity [88]. Moreover, the fat distribution of women with premature menopause did not differ from the fat distribution of postmenopausal women in the studied age interval.

The body fat mass of women with unexpected levels of sex hormones was related more to their hormonal levels than their menopausal status or their age, since premenopausal women with very low sex hormone levels had smaller amounts of body fat, while postmenopausal women with very high levels of sex hormone had a larger amount of body fat than their age-peers in their menopausal subgroups. However, the fat distribution of women showed a significant difference from the waist-to-hip ratio in the given menopausal subgroup only in the case of premenopausal women having very low levels of sex hormones, i.e. their waistto-hip ratio was higher, thus, their risk for abdominal obesity was higher than in their premenopausal age-peers. The relationship between sex hormone levels, nutritional status and reproductive ageing in the menopausal transition needs further investigation, because this is a menopause-related topic that has several clinical concerns as well. The results of the present analysis are in accord with the results published by one the few studies in this topic. Freeman et al. [89] reported that obese postmenopausal women had significantly higher estradiol levels compared to non-obese women after menopause.

The rate of reproductive ageing, the age at menopause, and the too early or too late onset of the final menopausal transition are of high importance. On the basis of our results it is highly recommended that researchers consider these reproductive parameters as well both sex hormone assessment and body composition analysis in epidemiological, anthropological and in gynaecological data collection and analysis.
Beside evidence for an increased risk of breast cancer in relation to an elevated free concentrations of, there is also a possible increase in risk with higher estradiol levels for breast cancer before age 50 years, namely before the menopausal transition[90-92]. This interrelation between the level of free estradiol and breast cancer risk in premenopausal women and the presented interrelation among the age at menopause, menopausal status, and body fatness may be considered as evidence for the clinical importance of this study in addition to the new epidemiological data on body composition changes during the menopausal transition from the aspect of menopausal status.

The complex relationship between fatness and female sex hormonal status in the female reproductive and postreproductive periods has not yet been fully explored, since the cause and effects have not been identified. For example both relations have been evidenced: (1) adipose tissue is one of the sources of oestrogen production, thereby higher fat accumulation can amplify the endogenous estradiol level, as well as (2) the above average level of estradiol increases the risk of abdominal obesity. Therefore, further longitudinal investigations are needed to understand this very complex, very strictly regulated transition of the female lifespan. However, not only the fat fraction but also the muscle fraction should be considered as body components in such studies, because of the endocrine function of the muscle tissue.

The decrease in ovarian hormone levels preceded the onset of the menopause in the studied sample (5-10 years earlier than the final menstruation cycle generally occurred). This indicator of the ageing of the neuroendocrine system should be considered seriously, since this physiological process, the decrease in the estradiol and progesterone levels - in addition to the decrease in inhibin B and AMH levels and the increase in FSH levels - could help predict the end of the reproductive period and could warn women and their health care providers about the beginning of the body structural and functional changes associated with the menopausal transition. It must be emphasized that the increasing level of FSH and the decreasing level of estradiol are currently accepted as the major endocrine markers of the menopausal transition in the clinical practice $[93,94]$. Both early and the late onsets of reproductive ageing in women lead to serious health consequences. Therefore the complex relationship between menopausal status, endocrine status, body composition and health risk emphasizes the importance of conscious weight control and regular screening for abnormal nutritional status and body composition in the menopausal transition. Besides the assessment of menopausal status, the estimation of sex hormone levels could help in the rating of body composition and the planning of lifestyle counseling or medical intervention.

\section{Limitations of the study}

The main limitation of the study was that saliva samples could be collected once from the subjects and not repeatedly during a menstrual cycle. This sample collection could provide only a weak estimation of hormonal level in relation to menstrual cycle stage. The division of subjects into subgroups with sex hormone level out of the normal range of the menopausal status, therefore, was also less reliable compared to longitudinal sample collection. Data on the average length of menstrual cycle and date of the last menstruation could help us to determine the menstrual cycle stage.

The other limitation of the study was that saliva samples and not blood samples were collected from subjects. Since saliva is a blood ultrafiltrate, only the level free concentration of sex hormones could be assessed. However, to decrease the effect of this limitation on the analysis, the normal ranges determined by the manufacturer (IBL, Hamburg, Germany) were used to divide subjects into hormone level subgroups, and saliva samples were collected from 
4 control subjects' saliva to estimate the real ranges of the studied sex hormones in the studied sample.

According to the actual scientific literature (e.g. Stages of Reproductive Aging Workshop+ 10 recommendations) [94] beside the steroid hormone levels the level of FSH is recommended for menopausal status estimation. The presented study was launched in 2011, when the steroid hormones themselves were also accepted for such an estimation, and moreover FSH levels cannot be estimated from saliva samples. Therefore the levels of free estradiol and free progesterone hormones were estimated by the IBL ELISA kits. Our future aim is to start a new longitudinal study by collecting a smaller sample of women, but estimating the level of not only the steroid sex hormones, but also FSH, inhibin B and AMH levels in different stages of the reproductive life.

\section{Competing interests}

\section{The authors declare no conflict of interest.}

\section{Ethical approval}

The presented study was carried out in accordance with The Code of Ethics of the World Medical Association (Declaration of Helsinki) for experiments involving humans and with the Uniform Requirements for manuscripts submitted to Biomedical journals.

All subjects were asked to give their informed consent to participate in the study. All participants were provided with detailed information on the main purposes of the study.

The research objectives, the research methodology and the questionnaires were approved by the National Human Research Ethics Committee $(108 / 2011)$ and the Hungarian Scientific Research Fund (EIK-1001/2011).

\section{Funding information}

The study was supported by the Hungarian Scientific Research Fund (OTKA grant K83966). The work of the first author was also supported by the Janos Bolyai Research Scholarship (2014-2017) of the Hungarian Academy of Sciences.

\section{List of contributors and their role in the paper}

Annamaria ZSAKAI contributed in the field-works, in the molecular biological examinations, in the statistical analysis, and in the data interpretation of the presented study.

Zsolt KARKUS contributed in the field-works, and in the data interpretation of the presented study.

Katinka UTCZAS contributed in the field-works, in the molecular biological examinations, and in the data interpretation of the presented study.

Beata BIRI contributed in the molecular biological examinations, and in the data interpretation of the presented study.

Lynnette L. SIEVERT contributed in the statistical analysis and in the data interpretation of the presented study.

Eva B BODZSAR contributed in the field-works, in the molecular biological examinations, in the statistical analysis, and in the data interpretation of the presented study.

\section{Acknowledgement}

The study was supported by the Hungarian Scientific Research Fund (OTKA grantK83966). The work of the first author was also supported by the Janos Bolyai Research Scholarship (2014-2017) of the Hungarian Academy of Sciences.

\section{References}

[1] C. Martins, L. Morgan, H. Truby, A review of the effects of exercise on appetite regulation: an obesity perspective, Int. J. Obes. 32 (9) (2008) 1337-1347.

[2] B.M. Spiegelman, J.S. Flier, Obesity and the regulation of energy balance, Cell 104 (4) (2001) 531-543.

[3] U. Meier, A.M. Gressner, Endocrine regulation of energy metabolism: review of pathobiochemical and clinical chemical aspects of leptin, ghrelin, adiponectin, and resistin, Clin. Chem. 50 (9) (2004) 1511-1525.

[4] M.D. Klok, S. Jakobsdottir, M.L. Drent, The role of leptin and ghrelin in the regulation of food intake and body weight in humans: a review, Obes. Rev. 8 (1) (2007) 21-34.

[5] P. Kaufert, P.P. Boggs, B. Ettinger, N.F. Woods, W.H. Utian, Women and menopause: beliefs, attitudes, and behaviors: the north American menopause society 1997 menopause survey, Menopause 5 (4) (1998) 197-202.

[6] J.E. Blumel, C. Castelo-Branco, L. Binfa, G. Gramegna, X. Tacla, B. Aracena, M.A. Cumsille, A. Sanjuan, Quality of life after the menopause: a population study, Maturitas 34 (1) (2000) 17-23.

[7] C.M. Obermeyer, Menopause across cultures: a review of the evidence, Menopause 7 (3) (2000) 184-192.

[8] Y.F. Zöllner, C. Acquadro, M. Schaefer, Literature review of instruments to assess health-related quality of life during and after menopause, Qual. Life Res. 14 (2) (2005) 309-327.

[9] K.E. Dennis, Postmenopausal women and the health consequences of obesity, J. Obstet. Gynecol. Neonat. Nur. 36 (5) (2007) 511-519.

[10] J.C. Gallagher, Effect of early menopause on bone mineral density and fractures, Menopause 14 (3) (2007) 567-571.

[11] L.T. Shuster, D.J. Rhodes, B.S. Gostout, B.R. Grossardt, W.A. Rocca, Premature menopause or early menopause: long-term health consequences, Maturitas 65 (2) (2010) 161-166

[12] G.S. Cooper, D.P. Sandler, Age at natural menopause and mortality, Ann. Epidemiol. 8 (4) (1998) 229-235.

[13] F.B. Hu, F. Grodstein, C.H. Hennekens, G.A. Colditz, M. Johnson, J.E. Manson, B. Rosner, M.J. Stampfer, Age at natural menopause and risk of cardiovascular disease, Arch. Int. Med 159 (10) (1999) 1061-1066.

[14] F. Atsma, M.L.E. Bartelink, D.E. Grobbee, Y.T. van der Schouw, Postmenopausal status and early menopause as independent risk factors for cardiovascular disease: a meta-analysis, Menopause 13 (2) (2006) 265-279.

[15] B.L. Harlow, L.B. Signorello, Factors associated with early menopause, Maturitas 35 (1) (2000) 3-9.

[16] A.C. Bagur, C.A. Mautalen, Risk for developing osteoporosis in untreated premature menopause, Calcified Tissue Int. 51 (1) (1992) 4-7.

[17] D.J. Hadjidakis, E.P. Kokkinakis, M.E. Sfakianakis, S.A. Raptis, Bone density patterns after normal and premature menopause, Maturitas 44 (4) (2003) 279-286.

[18] P. Luoma, A. Melberg, J.O. Rinne, J.A. Kaukonen, N.N. Nupponen, R.M. Chalmers, A. Oldfors, I. Rautakorpi, L. Peltonen, K. Majamaa, H. Somer, A. Suomalainen, Parkinsonism premature menopause, and mitochondrial DNA polymerase $\gamma$ mutations: clinical and molecular genetic study, Lancet 364 (9437) (2004) 875-882.

[19] P. Ragonese, M. D’amelio, G. Salemi, P. Aridon, M. Gammino, A. Epifanio, L. Morgante, G. Savettieri, Risk of Parkinson disease in women Effect of reproductive characteristics, Neurology 62 (11) (2004) 2010-2014.

[20] C. Li, G. Samsioe, C. Borgfeldt, J. Lidfeldt, C.D. Agardh, C. Nerbrand, Menopause-related symptoms: what are the background factors? A prospective population-based cohort study of Swedish women, Am. J. Obstet. Gynecol. 189 (6) (2003) 1646-1653

[21] M.E. Ossewaarde, M.L. Bots, A.L. Verbeek, P.H. Peeters, Y. van der Graaf, D.E. Grobbee, Y.T. van der Schouw, Age at menopause, cause-specific mortality and total life expectancy, Epidemiology 16 (4) (2005) 556-562.

[22] L.L. Sievert, L. Murphy, L.A. Morrison, A.M. Reza, D.E. Brown, Age at menopause and determinants of hysterectomy and menopause in a multi-ethnic community: the Hilo Women's Health Study, Maturitas 76 (4) (2013) 334-341.

[23] L.L. Sievert, Anthropology and the study of menopause: evolutionary, developmental, and comparative perspectives, Menopause 21 (10) (2014) 1151-1159.

[24] T.J. Key, P.K. Verkasalo, E. Banks, Epidemiology of breast cancer, Lancet Oncol. 2 (3) (2001) 133-140.

[25] Endogenous Hormones Breast Cancer Collaborative Group, Body mass index serum sex hormones, and breast cancer risk in postmenopausal women, J. Natl. Cancer I 95 (16) (2003) 1218-1226.

[26] L. Vaughan, F. Zurlo, E. Ravussin, Aging and energy expenditure, Am. J. Clin. Nutr. 53 (4) (1991) 821-825.

[27] S.B. Roberts, I. Rosenberg, Nutrition and aging: changes in the regulation of energy metabolism with aging, Physiol. Rev. 86 (2) (2006) 651-667.

[28] J.R. Speakman, K.R. Westerterp, Associations between energy demands, physical activity, and body composition in adult humans between 18 and $96 \mathrm{y}$ of age, Am. J. Clin. Nutr. 92 (4) (2010) 826-834.

[29] M.J. Toth, A. Tchernof, C.K. Sites, E.T. Poehlman, Effect of menopausal status on body composition and abdominal fat distribution, Int. J. Obesity 24 (2000) 226-231.

[30] E.T. Poehlman, Menopause, energy expenditure, and body composition, Acta Obstet. Gynecol. Scand. 81 (7) (2002) 603-611.

[31] M. Sowers, H. Zheng, K. Tomey, C. Karvonen-Gutierrez, M. Jannausch, X. Li, M. Yosef, J. Symons, Changes in body composition in women over six years at

\section{9}

$$
\begin{aligned}
& 56 \\
& 562 \\
& 56
\end{aligned}
$$

$$
\begin{aligned}
& 56 \\
& 566 \\
& 56 \\
& 56
\end{aligned}
$$

568



midlife: ovarian and chronological aging, J. Clin. Endocr. Metab. 92 (3) (2007) 895-901.

[32] H.N. Polotsky, A.J. Polotsky, Metabolic implications of menopause, Semin. Reprod. Med. 28 (5) (2010) 426-434.

[33] A. Tchernof, J.P. Despres, Pathophysiology of human visceral obesity: an update, Physiol. Rev. 93 (1) (2013) 359-404.

[34] G. Berg, V. Mesch, L. Boero, F. Sayegh, M. Prada, M. Royer, M.L. Muzzio, L. Schreier, N. Siseles, H. Benencia, Lipid and lipoprotein profile in menopausal transition Effects of hormones, age and fat distribution. Hormone and metabolic research, Horm. Metab. Res. 36 (4) (2004) 215-220.

[35] J.C. Lovejoy, C.M. Champagne, L. De Jonge, H. Xie, S.R. Smith, Increased visceral fat and decreased energy expenditure during the menopausal transition, Int. J. Obes. 32 (6) (2008) 949-958.

[36] J.L. Kuk, T.J. Saunders, L.E. Davidson, R. Ross, Age-related changes in total and regional fat distribution, Ageing Res. Rev. 8 (4) (2009) 339-348.

[37] A. Zsakai, N. Mascie-Taylor, E.B. Bodzsar, Relationship between body fatness in the menopause transition and the characteristics of the reproductive history, J. Physiol. Anthropol. (2015), in press.

[38] S.M. McKinlay, D.J. Brambilla, J.G. Posner, The normal menopause transition, Am. J Hum Biol 4 (1) (1992) 37-46.

[39] J.L. Luborsky, P. Meyer, M.F. Sowers, E.B. Gold, N. Santoro, Premature menopause in a multiethnic population the menopause transition, Hum. Reprod. 18 (1) (2002) 199-206.

[40] World Health Organization, The World Health Report 2008, Primary Health Care, Geneva, Switzerland : WHO, 2008

[41] T. Cole, H. Pan, LMS Program Version 1.29. A Program for Calculating Age-related Reference Centiles Using the LMS Method, Institute for Child Health, London, 2004.

[42] T.J. Cole, P.J. Green, Smoothing reference centile curves: the LMS method and penalized likelihood, Stat. Med. 11 (1992) 1305-1319.

[43] T. Matsukawa, Y. Sugiyama, T. Watanabe, F. Kobayashi, T. Mano, Gender difference in age-related changes in muscle sympathetic nerve activity in healthy subjects, Am. J. Physiol. Reg. I 275 (5) (1998) R1600-4.

[44] P.L. Torng, T.C. Su, F.C. Sung, K.L. Chien, S.C. Huang, S.N. Chow, Y.T. Lee, Effects of menopause on intraindividual changes in serum lipids, blood pressure, and body weight - the Chin-Shan Community Cardiovascular Cohort study, Atherosclerosis 161 (2) (2002) 409-415.

[45] C.C. Liu, T.B. Kuo, C.C. Yang, Effects of estrogen on gender-related autonomic differences in humans, Am. J. Physiol. Heart C 285 (5) (2003) H2188-93.

[46] North American Menopause Society, Treatment of menopause-associated vasomotor symptoms: position statement of The North American Menopause Society, Menopause 11 (1) (2004) 11-12.

[47] B.A. Sternfeld, A.K. Bhat, H. Wang, T. Sharp, C.P. Quesenberry, Menopause, physical activity, and body composition/fat distribution in midlife women, Med. Sci. Sports Exerc. 37 (7) (2005) 1195-1202.

[48] T. Douchi, S. Yamamoto, N. Yoshimitsu, T. Andoh, T. Matsuo, Y. Nagata, Relative contribution of aging and menopause to changes in lean and fat mass in segmental regions, Maturitas 42 (4) (2002) 301-306.

[49] J.S. Finkelstein, S.E. Brockwell, V. Mehta, G.A. Greendale, M.R. Sowers, B. Ettinger, J.C. Lo, J.M. Johnston, J.A. Cauley, M.E. Danielson, R.M. Neer, Bone mineral density changes during the menopause transition in a multiethnic cohort of women, J. Clin. Endoc. Metab. 93 (3) (2008) 861-868.

[50] R.M. Franklin, L. Ploutz-Snyder, J.A. Kanaley, Longitudinal changes in abdominal fat distribution with menopause, Metabolism 58 (3) (2009) 311-315.

[51] A. Zsakai, K. Utczas, B. Bodzsar, Changes of body composition in the menopausal transition (in Hungarian), Anthrop. Kozl. 54 (2013) 25-33.

[52] J.P. Despres, I. Lemieux, D. Prud'Homme, Treatment of obesity: need to focus on high risk abdominally obese patients, BMJ 322 (7288) (2001) 716

[53] A.H. Mokdad, E.S. Ford, B.A. Bowman, W.H. Dietz, F. Vinicor, V.S. Bales, J.S. Marks, Prevalence of obesity, diabetes, and obesity-related health risk factors, 2001, J. Am. Med. Assoc. 289 (1) (2003) 76-79.

[54] T. Lobstein, L. Baur, R. Uauy, Obesity in children and young people: a crisis in public health, Obes. Rev. 5 (s1) (2004) 4-85.

[55] P. Kopelman, Health risks associated with overweight and obesity, Obes. Rev. 8 (s1) (2007) 13-17.

[56] P.H. Van Baal, J.J. Polder, G.A. De Wit, R.T. Hoogenveen, T.L. Feenstra, H.C. Boshuizen, M. Engelfriet, W.B. Brouwer, Lifetime medical costs of obesity: prevention no cure for increasing health expenditure, PLoS Med. 5 (2) (2008) e29.

[57] World Health Organization, Global Health Risks: Mortality and Burden of Disease Attributable to Selected Major Risks, World Health Organization, 2009.

[58] Y.C. Wang. K. McPherson, T. Marsh, S.L. Gortmaker, M. Brown, Health and economic burden of the projected obesity trends in the USA and the UK, Lancet 378 (9793) (2011) 815-825.

[59] J.C. Seidell, Obesity, insulin resistance and diabetes-a worldwide epidemic, Br. J. Nutr. 83 (S1) (2000) S5-8.

[60] A.N. Vgontzas, D.A. Papanicolaou, E.O. Bixler, K. Hopper, A. Lotsikas, H.M. Lin, A. Kales, G.P. Chrousos, Sleep apnea and daytime sleepiness and fatigue: relation to visceral obesity, insulin resistance, and hypercytokinemia, J. Clin. Endocr. Metab. 5 (3) (2000) 1151-1158.

[61] F. Bianchini, R. Kaaks, H. Vainio, Overweight, obesity, and cancer risk, Lancet Oncol. 3 (9) (2002) 565-574.
[62] J. Hirosumi, G. Tuncman, L. Chang, C.Z. Görgün, K.T. Uysal, K. Maeda, M. Karin, G.S. Hotamisligil, A central role for JNK in obesity and insulin resistance, Nature 420 (6913) (2002) 333-336.

[63] R. Kaaks, A. Lukanova, M.S. Kurzer, Obesity, endogenous hormones, and endometrial cancer risk a synthetic review, Cancer Epidem. Biomar. Prev. 11 (12) (2002) 1531-1543.

[64] I. Juhan-Vague, M.C. Alessi, A. Mavri, P.E. Morange, Plasminogen activator inhibitor-1, inflammation, obesity, insulin resistance and vascular risk, J. Thromb. Haemost. 1 (7) (2003) 1575-1579.

[65] R. Wolk, A.S. Shamsuzzaman, V.K. Somers, Obesity, sleep apnea, and hypertension, Hypertension 42 (6) (2003) 1067-1074.

[66] P. Dandona, A. Aljada, A. Bandyopadhyay, Inflammation: the link between insulin resistance, obesity and diabetes, Trends Immunol. 25 (1) (2004) 4-7.

[67] G. Reaven, F. Abbasi, T. McLaughlin, Obesity, insulin resistance, and cardiovascular disease, Recent Prog. Horm. Res. 59 (2004) 207-224

[68] J.P. Bastard, M. Maachi, C. Lagathu, M.J. Kim, M. Caron, H. Vidal, J. Capeau, B. Feve, Recent advances in the relationship between obesity, inflammation, and insulin resistance, Eur. Cytokine Netw. 17 (1) (2006) 4-12.

[69] S.E. Kahn, R.L. Hull, K.M. Utzschneider, Mechanisms linking obesity to insulin resistance and type 2 diabetes, Nature 444 (7121) (2006) 840-846.

[70] R. Soltani-Arabshahi, B. Wong, B.J. Feng, D.E. Goldgar, K.C. Duffin, G.G. Krueger, Obesity in early adulthood as a risk factor for psoriatic arthritis, Arch. Dermatol. 146 (7) (2010) 721-726.

[71] World Health Organization, Obesity: Preventing and Managing the Global Epidemic. No. 894, WHO, Geneva, Switzerland, 2000.

[72] R.F. Florentino, The burden of obesity in Asia: challenges in assessment, prevention and management, Asia Pac. J. Clin. Nutr. 11 (s8) (2002) S676-80.

[73] W.P. Jia, K.S. Xiang, L. Chen, J.X. Lu, Y.M. Wu, Epidemiological study on obesity and its comorbidities in urban Chinese older than 20 years of age in Shanghai, China, Obesity Rev. 3 (3) (2002) 157-165.

[74] N. Cossrow, B. Falkner, Race/ethnic issues in obesity and obesity-related comorbidities, J. Clin. Endoc. Metab. 89 (6) (2004) 2590-2594.

[75] I. Janssen, P.T. Katzmarzyk, R. Ross, Waist circumference and not body mass index explains obesity-related health risk, Am. J. Clin. Nutr. 79 (2004) 379-384.

[76] P.W. Sullivan, E.H. Morrato, V. Ghushchyan, H.R. Wyatt, J.O. Hill, Obesity, inactivity, and the prevalence of diabetes and diabetes-related cardiovascular comorbidities in the US, 2000-2002, Diabetes Care 28 (7) (2005) 1599-1603.

[77] M. Bullo, P. Casas-Agustench, P. Amigo-Correig, J. Aranceta, J. Salas-Salvado, Inflammation, obesity and comorbidities: the role of diet, Public Health Nutr. 10 (10A) (2007) 1164-1172.

[78] O. Uzuner, Recognizing obesity and comorbidities in sparse data, J. Am. Med. Inform. Assn. 16 (4) (2009) 561-570.

[79] K.M. Gadde, D.B. Allison, D.H. Ryan, C.A. Peterson, B. Troupin, M.L. Schwiers, Day WW Effects of low-dose, controlled-release, phentermine plus topiramate combination on weight and associated comorbidities in overweight and obese adults (CONQUER): a randomised, placebo-controlled, phase 3 trial, Lancet 377 (9774) (2011) 1341-1352.

[80] M. Meschia, F. Pansini, A.B. Modena, D. de Aloysiod, M. Gambaccianie, F. Parazzinia, C. Campagnolif, G. Maiocchig, E. Peruzzi, Determinants of age at menopause in Italy: results from a large cross-sectional study: iCARUS Study Group. Italian Climacteric Research Group Study, Maturitas 34 (2000) 119-125.

[81] B.K. Jacobsen, I. Heuch, G. Kvale, Age at natural menopause and allcause mortality: a 37-year follow-up of 19,731 Norwegian women, Am. J. Epidemiol. 157 (2003) 923-929.

[82] D.A. Lawlor, S. Ebrahim, G.D. Smith, The association of socio-economic position across the life course and age at menopause: the British Women's Heart and Health Study, BJOG 110 (2003) 1078-1087.

[83] K. Rodstrom, C. Bengtsson, I. Milsom, L. Lissner, V. Sundh, C. Bjourkelund, Evidence for a secular trend in menopausal age: a population study of women in Gothenburg, Menopause 10 (2003) 538-543.

[84] R.F. Reynolds, C.M. Obermeyer, Age at natural menopause in Spain and the United States: results from the DAMES project, Am. J. Hum. Biol. 17 (2005) $331-340$.

[85] M. Kaczmarek, The timing of natural menopause in Poland and associated factors, Maturitas 57 (2007) 139-153.

[86] J. Dratva, E. Zemp, P. Staedele, C. Schindlera, M. Constanzad, M. Gerbaseb, N. Probst-Henschc, T. Rochatd, U. Ackermann-Liebrich, Variability of reproductive history across the Swiss SAPALDIA cohortVpatterns and main determinants, Ann. Hum. Biol. 34 (2007) 437-453.

[87] J. Dratva, F.G. Real, C. Schindler, U. Ackermann-Liebrich, M.W. Gerbase, N.M Probst-Hensch, C. Svanes, E.R. Omenaas, F. Neukirch, M. Wjst, A. Morabia, D. Jarvis, B. Leynaert, E. Zemp, Is age at menopause increasing across Europe? Results on age at menopause and determinants from two population-based studies, Menopause 16 (2) (2009) 385-394.

[88] E.B. Bodzsar, C. Susanne, Physique and body composition-variability and sources of variation biennial book of EAA 3, Plantin press, Budapest, 2004

[89] E.W. Freeman, M.D. Sammel, H. Lin, C.R. Gracia, Obesity and reproductive hormone levels in the transition to menopause, Menopause 17 (4) (2010) 718-726.

[90] R. Kaaks, F. Berrino, T. Key, S. Rinaldi, L. Dossus, C. Biessy, G. Secreto, P. Amiano, S. Bingham, H. Boeing, H.B.B. de Mesquita, J. Chang-Claude, F. Clavel-Chapelon, A. Fournier, C.H. van Gils, C.A. Gonzalez, A. Barricarte Gurrea, E. Critselis, K.T. Khaw, V. Krogh, P.H. Lahmann, G. Nagel, A. Olsen, N.C. Onland-Moret, K. Overvad, D. Palli, S. Panico, P. Peeters, J.R. Quiros, A.

\section{8}

660

662

\section{664
665}

\section{667}

$$
669
$$

\section{671}

$$
\begin{aligned}
& 673 \\
& 674
\end{aligned}
$$

\section{5}

\section{678}

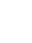 \\ 679
680}

\section{\begin{tabular}{l}
68 \\
682 \\
\hline
\end{tabular}}$$
\begin{aligned}
& 684 \\
& 685 \\
& 686
\end{aligned}
$$

68
688

689
690

$$
\begin{aligned}
& 691 \\
& 692 \\
& 693
\end{aligned}
$$

\section{694}

695

\section{698}

699
700
70

\section{702
703}

\section{704
705}

\section{706
707}

\section{709}

\section{71}

\section{713}

\section{715
716}

716
717
718

\section{719
720}

\section{722
72
72}

720
721
722
723

\section{724
725}

$$
\begin{aligned}
& 724 \\
& 725 \\
& 726 \\
& 727
\end{aligned}
$$

$$
\begin{aligned}
& 726 \\
& 727 \\
& 728 \\
& 729
\end{aligned}
$$

$$
\begin{aligned}
& 728 \\
& 729 \\
& 730
\end{aligned}
$$

$$
\begin{aligned}
& 729 \\
& 730 \\
& 731
\end{aligned}
$$

$$
\begin{aligned}
& 731 \\
& 732 \\
& 733
\end{aligned}
$$$$
733
$$

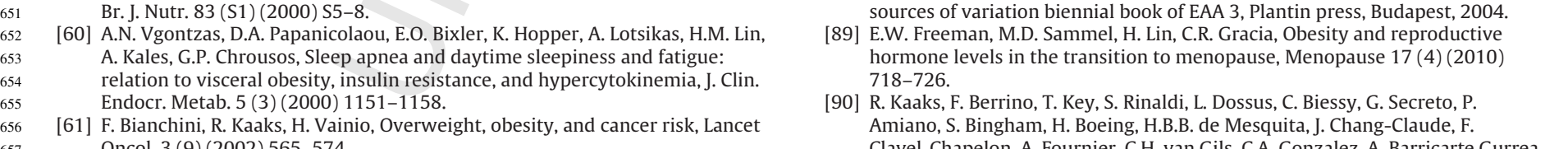

E. Critselis, K.T. Khaw, V. Krogh, P.H. Lahmann, G. Nagel, A. Olsen, N.C.
Onland-Moret, K. Overvad, D. Palli, S. Panico, P. Peeters, J.R. Quiros, A.


Roddam, A. Thiebaut, A. Tjonneland, D. Chirlaque, A. Trichopoulou, D. Trichopoulos, R. Tumino, P. Vineis, T. Norat, P. Ferrari, N. Slimani, E. Riboli, Serum sex steroids in premenopausal women and breast cancer risk within the European Prospective Investigation into Cancer and Nutrition (EPIC), J. Nat. Cancer Inst. 97 (10) (2005) 755-765.

[91] A.H. Eliassen, S.A. Missmer, S.S. Tworoger, D. Spiegelman, R.L. Barbieri, M. Dowsett, S.E. Hankinson, Endogenous steroid hormone concentrations and risk of breast cancer among premenopausal women, J. Natl. Cancer I 98 (19) (2006) 1406-1415.

[92] R. Kaaks, K. Tikk, D. Sookthai, H. Schock, T. Johnson, A. Tjonneland, A. Olsen, K. Overvad, F. Clavel-Chapelon, L. Dossus, L. Baglietto, S. Rinaldi, V. Chajes, I. Romieu, H. Boeing, M. Schütze, A. Trichopoulou, P. Lagiou, D. Trichopoulos, D. Palli, S. Sieri, R. Tumino, F. Ricceri, A. Mattiello, G. Buckland, J.R. Quiros, M.J. Sanchez, P. Amiano, M.D. Chirlaque, A. Barricarte, H.B. Bueno-de-Mesquita,
C.H. van Gils, P.H. Peeters, A. Andersson, M. Sund, E. Weiderpass, K.T. Khaw, N. Wareham, T.J. Key, R.C. Travis, M.A. Merritt, M.J. Gunter, E. Riboli, A. Lukanova, Premenopausal serum sex hormone levels in relation to breast cancer risk, overall and by hormone receptor status-results from the EPIC cohort, Int. J. Cancer 134 (8) (2014) 1947-1957.

[93] M.R. Sowers, A.D. Eyvazzadeh, D. McConnell, M. Yosef, M.L. Jannausch, D. Zhang, S. Harlow, J.F. Randolph, Anti-mullerian hormone and inhibin B in the definition of ovarian aging and the menopause transition, J. Clin. Endocrinol. Metab. 93 (9) (2008) 3478-3483.

[94] S.D. Harlow, M. Gass, J.E. Hall, R. Lobo, P. Maki, R.W. Rebar, S. Sherman, P.M. Sluss, T.J. de Villiers, Executive summary of the stages of reproductive aging workshop+10: addressing the unfinished agenda of staging reproductive aging, Climacteric 15 (2) (2012) 105-114 